\title{
The use of sugammadex for bariatric surgery: analysis of recovery time from neuromuscular blockade and possible economic impact
}

This article was published in the following Dove Press journal:

ClinicoEconomics and Outcomes Research

29 June 2016

Number of times this article has been viewed

\author{
Edoardo De Robertis' \\ Geremia Zito Marinosci' \\ Giovanni Marco Romano' \\ Ornella Piazza ${ }^{2}$ \\ Michele Iannuzzi' \\ Fabrizio Cirillo' \\ Stefania De Simone ${ }^{3}$ \\ Giuseppe Servillo' \\ 'Department of Neurosciences, \\ Reproductive and \\ Odontostomatologic Sciences, \\ University Federico II, Naples, \\ ${ }^{2}$ Department of Medicine and Surgery, \\ University of Salerno, Salerno, \\ ${ }^{3}$ Institute for Research on Innovation \\ and Services for Development, \\ National Research Council, \\ Naples, Italy
}

Correspondence: Edoardo De Robertis Department of Neurosciences,

Reproductive and Odontostomatologic Sciences, University Federico II, Naples, via S. Pansini 5, 80I 3 I, Italy

Tel+3908I 746355042

Email ederober@unina.it
Background: Neuromuscular block (NMB) monitoring and use of reversal agents accelerate the recovery time and improve the workflow in the operating room. We aimed to compare recovery times after sugammadex or neostigmine administration, and estimate the time spent in operating theater and the possible economic impact of a faster recovery, in morbidly obese patients undergoing bariatric surgery.

Methods: We conducted a retrospective study that analyzed data from records of morbidly obese patients (body mass index $>40 \mathrm{~kg} / \mathrm{m}^{2}$ ) undergoing elective laparoscopic bariatric surgery in which sugammadex or neostigmine were used to reverse NMB. Patients were divided in two groups: group 1 (sugammadex group [SUG]) received rocuronium and sugammadex for reversal and group 2 (neostigmine group [NEO]) received either rocuronium or cisatracurium and neostigmine. Data are presented as mean (standard deviation).

Results: Compared with NEO, SUG group showed shorter times to achieve train-of-four ratio of $0.9(P<0.05)$ and an Aldrete score of $10(P<0.05)$, a higher cost $(€ 146.7$ vs $€ 3.6[P<0.05])$, plus a remarkable less duration of operating theater occupancy $(P<0.05)$. Sugammadex cost accounted for $2.58 \%$ of the total cost per surgery, while neostigmine cost accounted for $0.06 \%$. Total time saved in SUG group was 19.4 hours, which could be used to perform 12 extra laparoscopic sleeve gastrectomies.

Conclusion: Reversal from NMB was significantly faster with sugammadex than with neostigmine. Although sugammadex was substantially more expensive, duration of operating theater occupancy was reduced with potentially workflow increase or personnel reduced cost.

Keywords: PORC, pharmacoeconomics, laparoscopic surgery, reversal agents

\section{Introduction}

In Western countries, obesity, defined as a body mass index (BMI) $\geq 30 \mathrm{~kg} / \mathrm{m}^{2}$, is reaching the proportions of an epidemic. ${ }^{1,2}$

Lifestyle interventions are seldom associated with long-lasting results. ${ }^{3}$ Accordingly, requests for bariatric surgery have dramatically increased in recent years, ${ }^{4}$ with the majority of the procedures performed through laparoscopic approach, which is a valid option to open surgery and demonstrated to reduce major complications. ${ }^{5}$ In Italy, 11,483 bariatric surgeries have been performed in 2015, with a laparoscopic approach in $97 \%$ of cases. ${ }^{6}$

On the other hand, perioperative management of morbidly obese patients is undoubtedly challenging for anesthesiologists. General anesthesia and paralysis may cause respiratory impairment. Nevertheless, neuromuscular blockade may be important during laparoscopic surgery in order to optimize ventilation and maintain an adequate 
pneumoperitoneum. ${ }^{7}$ Nonetheless, correct dosing of nondepolarizing neuromuscular blocking agents should be calculated according to ideal body weight in order to avoid extended duration of action ${ }^{8-10}$ and postoperative residual curarization (PORC). Anesthesia provider should promote a reliable and full recovery from neuromuscular blockade after surgery. PORC may potentially induce adverse respiratory events ${ }^{11}$ and its frequency is often underrated: $\sim 30 \%$ of all patients receiving a neuromuscular blocking drug show signs of impaired activity and coordination of the pharyngoesophageal muscles, and this may result in an increased incidence of complications after anesthesia. ${ }^{11}$ Close monitoring of neuromuscular function has been recognized as an effective way to lower the occurrence of PORC and related pulmonary complications. ${ }^{11-13}$ PORC increases the risk of critical respiratory events, ${ }^{11}$ due to an impaired activity and coordination of the pharyngoesophageal muscles. ${ }^{14,15}$ A train-of-four (TOF) ratio $<0.9$ has shown to be associated with a heightened risk of pulmonary complication. ${ }^{14,15}$ In addition, neuromuscular blocking agents smooth the ventilatory response to hypoxia, and may increase the risk of respiratory impairment. ${ }^{16}$ Accordingly, use of antagonists, either acetylcholinesterase inhibitor (AChEI) or sugammadex, is strongly recommended when there is evidence of an incomplete recovery from neuromuscular blockade (TOF ratio <0.9). ${ }^{17}$

To monitor neuromuscular blockade, anesthesiologists may use acceleromyography-based monitoring. A TOF ratio of 1.0 represents complete recovery from paralysis, while residual neuromuscular block (NMB) is defined as a TOF ratio of $<0.9$; the latter is associated with impairment in swallowing, airway obstruction, and heightened risk of gastric content aspiration. ${ }^{14,15}$

In this study, we analyzed and compared the costs and the recovery times after sugammadex or neostigmine administration, and estimated the time of operating theater occupancy (time from "starting anesthesia" to when the patient was transferred to the postanesthesia care unit [PACU]), in morbidly obese patients undergoing bariatric surgery.

\section{Materials and methods}

After obtaining ethical committee approval (University of Naples Federico II - 188/13), we conducted a retrospective analysis by searching in the hospital database, using the International Classification of Diseases 9th Revision code for bariatric surgery. Due to the retrospective nature of the study, the local ethics committee (University of Naples Federico II) did not find it necessary to obtain specific written informed patient consent.

Patients were considered eligible, if they conformed to the following inclusion criteria: age $>18$ and $<45$ years,
BMI $\geq 40 \mathrm{~kg} / \mathrm{m}^{2}$, and American Society of Anaesthesiologists class III, and no planned intensive care unit admission. Exclusion criteria were the planned or unplanned admission to intensive care unit, surgery lasting more than 3 hours, redo surgery (second bariatric surgical intervention with a more efficacious effect on weight loss), extremely morbidly obesity $\left(\mathrm{BMI}>60 \mathrm{~kg} / \mathrm{m}^{2}\right)$. Other exclusion criteria were the presence of comorbid conditions such as neuromuscular disorders, liver or renal dysfunction, and history of malignant hyperthermia.

The following anesthesiological procedure is the standard protocol in our institution: induction of general anesthesia is performed administering propofol $1-2 \mathrm{mg} / \mathrm{kg}$ and remifentanil $0.25-0.5 \mu \mathrm{g} / \mathrm{kg} / \mathrm{min}$ and maintained with sevoflurane and remifentanil $0.15-0.3 \mu \mathrm{g} / \mathrm{kg} / \mathrm{min}$. Standard monitoring consists of five-lead electrocardiography, pulse oximetry, end-tidal carbon dioxide, and noninvasive blood pressure monitoring. Neuromuscular monitoring is performed using acceleromyography (TOF-Watchw SX and TOF-Watch SX Monitoring Program, Organon Ireland Ltd., Dublin, Ireland), evaluating TOF at the adductor pollicis muscle. Neuromuscular blockade is obtained with either rocuronium $1.2 \mathrm{mg} / \mathrm{kg}$ or cisatracurium $0.2 \mathrm{mg} / \mathrm{kg}$. Maintenance doses of rocuronium $0.15 \mathrm{mg} / \mathrm{kg}$ or of cisatracurium $0.03 \mathrm{mg} / \mathrm{kg}$ are given as required to keep the neuromuscular blockade depth at $15 \%$ of first twitch (T1). Patients receive rocuronium or cisatracurium based on ideal body weight. ${ }^{18}$

At the end of surgery, sugammadex $2.0 \mathrm{mg} / \mathrm{kg}$ as a single dose or neostigmine $50 \mu \mathrm{g} / \mathrm{kg}$ plus atropine $0.01 \mathrm{mg} / \mathrm{kg}$ is given at the reappearance of two twitches on the TOF recording. Patients are extubated in the operating room (OR) when a TOF ratio of 0.9 is achieved and then transferred to the recovery room. In the recovery room, vital parameters and Aldrete score are recorded.

Data for analysis were retrieved from clinical charts, anesthesia charts, and PACU records.

Our primary end point was comparing the latency to achieve a TOF ratio $>0.9$ after reversal agents administration, the mean time to achieve an Aldrete score of 10, and the cost associated with these drugs. Our secondary end points were to evaluate the duration of operating theater occupancy, to identify the incidence of postoperative desaturation in PACU, and to evaluate the length of stay in hospital.

Data are presented as mean (standard deviation) and were compared using the Wilcoxon rank sum test or MannWhitney $U$ test. A $P<0.05$ was considered to be statistically significant. The statistical analysis was performed using SPSS for Windows, Version 10.1 (SPSS Inc., Chicago, IL, USA). 


\section{Results}

The overall number of elective laparoscopic bariatric surgery performed in our institution (University of Naples Federico II) from 2009 to 2013 was 321.

In our analysis, we included 99 patients who fulfilled inclusion criteria, allocating them in one of the two groups: in group 1 ( $\mathrm{n}=50-\mathrm{SUG}$ ), rocuronium administration was used for neuromuscular paralysis and sugammadex was used for reversal; in group 2 ( $n=49$ - NEO), rocuronium (35 patients) or cisatracurium (14 patients) were used for neuromuscular paralysis and neostigmine for reversal. Table 1 presents the

Table I Demographic data and surgical interventions

\begin{tabular}{lll}
\hline Patients characteristics & $\begin{array}{l}\text { SUG } \\
\text { (50 patients) }\end{array}$ & $\begin{array}{l}\text { NEO } \\
\text { (49 patients) }\end{array}$ \\
\hline Age (years) & $30.9(5.4)$ & $29.6(5.5)$ \\
Sex male/female $(\mathrm{n})$ & $32 / 18$ & $30 / 19$ \\
Weight $(\mathrm{kg})$ & $123.5(14.6)$ & $128.3(18.8)$ \\
Height $(\mathrm{cm})$ & $167.4(6.3)$ & $166.4(5.5)$ \\
BMI $\left(\mathrm{kg} / \mathrm{m}^{2}\right)$ & $44(4.7)$ & $46(6.8)$ \\
Laparoscopic sleeve gastrectomy $(\mathrm{n})$ & 13 & 12 \\
Laparoscopic adjustable gastric band $(\mathrm{n})$ & 34 & 35 \\
Laparoscopic biliopancreatic & 3 & 2 \\
diversion $(\mathrm{n})$ & & \\
\hline
\end{tabular}

Note: Data are mean (standard deviation) or number.

Abbreviations: BMI, body mass index; NEO, neostigmine group; SUG, sugammadex group.

Table 2 Pharmacological data and costs of reversal drugs

\begin{tabular}{|c|c|c|}
\hline & $\begin{array}{l}\text { SUG } \\
\text { (50 patients) }\end{array}$ & $\begin{array}{l}\text { NEO } \\
\text { (49 patients) }\end{array}$ \\
\hline Rocuronium (mg) & 73.3 (1.9) & $72.2(2.5)$ \\
\hline Cisatracurium (mg) & - & $15.6(0.9)$ \\
\hline Sugammadex (mg) & $258.8(58.4)$ & - \\
\hline Neostigmine (mg) & - & $6.4(0.9)$ \\
\hline $\begin{array}{l}\text { Mean time to obtain an Aldrete score } \\
\text { of } 10 \text { (minutes) }\end{array}$ & $16(1.8)^{*}$ & $21.8(2.8)$ \\
\hline $\begin{array}{l}\text { Time to achieve a TOF ratio of } \\
0.9 \text { (minutes) }\end{array}$ & $1.4(0.4)^{*}$ & $26.4(5.9)$ \\
\hline $\begin{array}{l}\text { Duration of laparoscopic sleeve } \\
\text { gastrectomy (minutes) }\end{array}$ & $86.4(5)$ & $87.8(4)$ \\
\hline $\begin{array}{l}\text { Duration of laparoscopic adjustable } \\
\text { gastric band (minutes) }\end{array}$ & $39(2)$ & $38.5(3)$ \\
\hline $\begin{array}{l}\text { Duration of laparoscopic } \\
\text { biliopancreatic diversion (minutes) }\end{array}$ & I53.5 (3) & $152.3(2)$ \\
\hline $\begin{array}{l}\text { Mean duration of operating theater } \\
\text { occupancy (minutes) }\end{array}$ & $93.3(54)^{*}$ & $116.6(67)$ \\
\hline $\mathrm{SpO}_{2}$ at PACU admission (\%) & $96(2)$ & $95(3)$ \\
\hline $\mathrm{SpO}_{2}$ at PACU discharge (\%) & $97(2)$ & $95(I)$ \\
\hline Mean cost of reversal agents $(€) \uparrow$ & $146.7^{*}$ & 3.6 \\
\hline Length of stay (days) & $4.2(1.8)$ & $3.9(1.9)$ \\
\hline
\end{tabular}

Notes: Data are mean (standard deviation); ${ }^{*} P<0.05$, Wilcoxon rank sum test or Mann-Whitney $U$ test; $\uparrow$ one vial of sugammadex $(200 \mathrm{mg})$ costs $€ I I 3$, while one vial of neostigmine $(0.5 \mathrm{mg})$ costs $€ 0.28$.

Abbreviations: PACU, postanesthesia care unit; TOF, train-of-four; NEO, neostigmine group; SUG, sugammadex group. characteristics of the patients and surgery. Duration of surgeries was not significantly different between the two groups (Table 2).

In the SUG group, the mean recovery time from reversal administration to a TOF ratio $\geq 0.9$ was quicker than in NEO group (1.4 [0.4] minutes vs 26.4 [5.9] minutes, $P<0.05)$ and all patients who received sugammadex recovered to a TOF ratio $>0.9$ within 5 minutes from its administration. SUG group experienced a remarkable less duration of operating theater occupancy (time from starting anesthesia till time that the patient was transferred to the PACU) compared with NEO (93.3 [54] minutes vs 116.6 [67] minutes, $P<0.05$ ). The mean time to obtain an Aldrete score of 10 (indicating that these patients were ready to be discharged from PACU) was 16 (1.8) minutes in SUG group and 21.8 (2.8) minutes in NEO group $(P<0.05)$. There were no significant differences in $\mathrm{SpO}_{2}$ at $\mathrm{PACU}$ admissions or discharge and in length of stay in hospital between the two groups.

The sugammadex dose used to reverse neuromuscular paralysis was 258.8 (58.4) $\mathrm{mg}$ (Table 2), and the mean cost per treatment was $€ 146.7$. In NEO group, the mean dosage to reverse neuromuscular paralysis was $6.4(0.9) \mathrm{mg}$ and the calculated cost per treatment was $€ 3.6$.

Our health system assigns for the three bariatric procedures we included in our analysis (laparoscopic sleeve gastrectomy, laparoscopic adjustable gastric band, laparoscopic biliopancreatic diversion) the same reimbursement of $€ 5,681$. Consequently, the cost of sugammadex accounted for the $2.58 \%$ of the total cost per surgery, while the neostigmine cost accounted for $0.06 \%$. However, the mean time saved using sugammadex instead of neostigmine was 23 minutes (Table 3). Total time saved for all the procedures done in the SUG group was 19.4 hours, while the total cost due to sugammadex use was $€ 7,335$.

An analysis of the economic impact of sugammadex use in our study (Table 3) shows that 12 extra laparoscopic sleeve gastrectomies could be carried out with the time saved by sugammadex. The reimbursement for these extra surgical

Table 3 Economic impact on 50 bariatric surgical procedures using sugammadex in place of neostigmine

\begin{tabular}{ll}
\hline Mean time saved using sugammadex & 23.3 minutes \\
Total time saved by sugammadex use ( $n=50$ procedures) & 19.4 hours \\
Total cost due to sugammadex use ( $\mathrm{n}=50$ procedures) & $€ 7,335$ \\
Extra laparoscopic sleeve gastrectomies, which could be & 12 \\
done with time saved using sugammadex & \\
Reimbursement for each bariatric procedure performed & $€ 5,681$ \\
Reimbursement for extra surgical procedures ( $n=12)$ & $€ 68,172$ \\
Sugammadex cost for all surgical procedures ( $n=50+12)$ & $€ 9,095$ \\
Total net gain in terms of reimbursement & $€ 59,077$ \\
Net gain in terms of reimbursement for each ( $n=50+12)$ & $€ 952.8$ \\
surgery & \\
\hline
\end{tabular}


procedures would be $€ 68,172$ with a cost of sugammadex for all surgical procedures $(n=50+12)$ of $€ 9,095$. Subtracting the cost due to sugammadex, the total net gain (€68,172 $€ 9,095)$ in terms of reimbursement would be $€ 59,077$ and the net gain for all surgeries $(n=50+12)$ in terms of reimbursement would be $€ 952.8(59,077 € / 50+12)$. As a result, $€ 1$ of sugammadex may generate $€ 6.5$ of reimbursement (€952.8/€146.7).

\section{Discussion}

In this retrospective analysis, we evidenced that sugammadex accelerated recovery from NMB and may bring potential favorable economic implication.

Extended routine monitoring of neuromuscular function may be particularly advantageous and may reduce the frequency of residual neuromuscular blockade. ${ }^{19,20}$ Evidences from literature report that many clinicians do not routinely use reversal agents before extubation. ${ }^{21,22}$ Use of antagonists, either AChEI or sugammadex, may help in preventing incomplete recovery from neuromuscular blockade (TOF ratio <0.9). ${ }^{17}$ Sugammadex, a new reversal of neuromuscular blockade, encapsulates rocuronium in a stable complex which is excreted and removed by the kidney, while AChEIs augment acetylcholine availability at the neuromuscular junction. The efficacy of AChEIs is limited by the "ceiling effect" in which additional doses have no further effect when there is a complete inhibition of all cholinesterases. ${ }^{23,24}$ Furthermore, AChEIs are associated with vagal reactions, autonomic instability, and nausea and vomiting. ${ }^{25}$ Nowadays, it is widely ascertained that sugammadex induces a faster recovery from rocuronium muscular block than AChEIs, independently from the depth of the block. ${ }^{26}$ Anyway, the high cost associated with sugammadex limits its use in routine clinical practice, where a clear benefit, from an economic perspective, is evident only when the time saved from recovery is used for more productivity. ${ }^{27}$ In our study, the faster recovery rate of SUG group shortened the duration of operating theater occupancy by a mean time of 23 minutes. It is necessary to clarify that the time saved by sugammadex is related to anesthesia period and other variables (nurse staff, room sterilization, skills of anesthesiologists and surgeons, etc) may influence the time of operating theater occupancy. On the other hand, even if sugammadex cost accounted for the $2.58 \%$ of the cost per surgery, total time saved for all the procedures in which sugammadex was used was 19.4 hours compared with neostigmine. Consequently, we may speculate that the rocuronium/sugammadex regimen would allow us to perform an other 12 laparoscopic sleeve gastrectomies. The time saved by sugammadex could be employed not only for more productivity, but also to reduce costs associated with operating room occupancy (ie, personnel).

Carron et $\mathrm{al}^{28}$ conducted a retrospective study showing that sugammadex use may reduce the risk of PORC, with an estimated cost-saving of $€ 2.9 /$ case. The authors concluded that the increased turnover and workflow using sugammadex clearly outweigh its high cost.

This figure is similar to the findings of an earlier simulation-based analysis, in which the authors concluded that the reduced recovery time could increase the number of cases by $2.4 \%$ over a 3 -month period. ${ }^{29}$ As stated elsewhere, this kind of economic analysis does not reflect clinical recommendations ${ }^{27}$ or, as in our experience, the complexity of the reimbursement fees from the regional health system in Italy. Moreover, the cost of sugammadex can vary substantially in different regions, making it difficult to reach any broader pharmacoeconomic conclusions. As shown in a recent systematic review, ${ }^{30}$ sugammadex may be cost-effective only when the time saved in the operating theater is spent in productivity. This assumption seems not applicable for the time saved in the recovery room. ${ }^{30}$

On the other hand, it is still unclear if sugammadex administration is associated with a better postoperative outcome. ${ }^{31}$ A randomized study ${ }^{32}$ in morbidly obese patients showed that the use of sugammadex was associated with a TOF ratio $>0.9$ (assessed using acceleromyography) in PACU, while neostigmine was not. However, it is worth mentioning that TOF ratio assessed by acceleromyography may be not reliable and accurate in awake patients. ${ }^{33}$ Carron et al ${ }^{34}$ have shown that sugammadex use is associated with a faster and safer recovery profile from neuromuscular blockade than neostigmine in morbidly obese patients, making it suitable for a fast-track bariatric surgery. Another prospective study in patients undergoing laparoscopic bariatric surgery evidenced that the frequency of postoperative mechanical ventilation requirement was not different, if neuromuscular blockade was reverted with sugammadex or neostigmine. ${ }^{35}$ Perhaps, sugammadex may be clinically useful in reducing postoperative adverse respiratory events in patients at risk, such as in elderly patients with American Society of Anaesthesiologists status of three or more. ${ }^{36}$ More recently, a randomized trial ${ }^{37}$ involving patients undergoing abdominal surgery has shown that sugammadex use was associated with full recovery from NMB, while $43 \%$ of patients in the neostigmine group experienced signs (TOF ratio $<0.9$ 
in PACU) of residual curarization. Also the discharge time was faster for patients in the sugammadex group. Although not powered for showing differences in pulmonary function compromise, postoperative respiratory complications were similar in the two groups.

In our study, we did not find desaturation in PACU and differences in length of stay in both groups, suggesting that major pulmonary complication did not occur.

An European prospective multicenter observational study (ClinicalTrials.gov website: NCT01865513) named POstanaesthesia PULmonary complications After use of muscle Relaxants has been recently sponsored by the European Society of Anaesthesia. This project aims to evaluate the effects of management of neuromuscular blockade on postoperative pulmonary complications in a general anesthetized population. The POstanaesthesia PULmonary complications After use of muscle Relaxants trial will investigate if the technique of neuromuscular monitoring influences the risk for postoperative pulmonary complications. Hopefully, the role of TOF will be cleared and a solid basis for implementing its use will be consolidated. ${ }^{38}$

\section{Limitations}

The main limitations of this study are its retrospective nonrandomized, single-center design, and the exclusion of extremely morbidly obese (BMI $>60 \mathrm{~kg} / \mathrm{m}^{2}$ ) patients. As cisatracurium and rocuronium were both considered in the analysis, we may not rule out the presence of an analytical bias. Moreover, the time saved by sugammadex is related to anesthesia period and other variables may influence the time of operating theater occupancy. We did not record TOF ratio at PACU, but we considered the Aldrete score as a clinical index of full recovery from NMB.

\section{Conclusion}

The clinical application of a TOF-driven protocol to reverse neuromuscular paralysis in morbidly obese patients should be encouraged. Sugammadex use is associated with a faster recovery and a higher health care costs. However, the main benefit is the time saved in the operating room, which could be used in more productivity, such as increasing the number of surgical procedures to perform.

\section{Author contributions}

All the authors have contributed substantially to the conception and design of the study, to the acquisition, analysis, and interpretation of data. They have contributed in drafting the manuscript and in revising it critically for the final approval.

\section{Disclosure}

No external funding was declared. The authors report no conflicts of interest in this work.

\section{References}

1. Catenacci VA, Hill JO, Wyatt HR. The obesity epidemic. Clin Chest Med. 2009;30(3):415-444, vii.

2. Whitlock G, Lewington S, Sherliker P, et al. Body-mass index and cause-specific mortality in 900000 adults: collaborative analyses of 57 prospective studies. Lancet. 2009;373(9669):1083-1096.

3. Li G, Zhang P, Wang J, et al. The long-term effect of lifestyle interventions to prevent diabetes in the China Da Qing Diabetes Prevention Study: a 20-year follow-up study. Lancet. 2008;371(9626): 1783-1789.

4. Douglas IJ, Bhaskaran K, Batterham RL, Smeeth L. Bariatric surgery in the United Kingdom: a cohort study of weight loss and clinical outcomes in routine clinical care. PLoS Med. 2015;12(12): e1001925.

5. Benaiges D, Más-Lorenzo A, Goday A, et al. Laparoscopic sleeve gastrectomy: more than a restrictive bariatric surgery procedure? World $J$ Gastroenterol. 2015;21(41):11804-11814.

6. Italian Society of Obesity Surgery and Metabolic Diseases - Survey 2015. Available from: http://www.sicob.org/00_materiali/area_medici/indagine Indagine_conoscitiva_2015_20160524.pdf. Accessed May 24, 2016.

7. Kuruba R, Koche LS, Murr MM. Preoperative assessment and perioperative care of patients undergoing bariatric surgery. Med Clin North Am. 2007;91(3):339-351, ix.

8. Leykin Y, Pellis T, Lucca M, Lomangino G, Marzano B, Gullo A. The pharmacodynamic effects of rocuronium when dosed according to real body weight or ideal body weight in morbidly obese patients. Anesth Analg. 2004;99(4):1086-1089.

9. Leykin Y, Pellis T, Lucca M, Lomangino G, Marzano B, Gullo A. The effects of cisatracurium on morbidly obese women. Anesth Analg. 2004;99(4):1090-1094.

10. Schwartz AE, Matteo RS, Ornstein E, Halevy JD, Diaz J. Pharmacokinetics and pharmacodynamics of vecuronium in the obese surgical patient. Anesth Analg. 1992;74(4):515-518.

11. Murphy GS, Szokol JW, Marymont JH, Greenberg SB, Avram MJ, Vender JS. Residual neuromuscular blockade and critical respiratory events in the postanesthesia care unit. Anesth Analg. 2008;107(1):130-137.

12. Berg H, Roed J, Viby-Mogensen J, et al. Residual neuromuscular block is a risk factor for postoperative pulmonary complications. A prospective, randomised, and blinded study of postoperative pulmonary complications after atracurium, vecuronium and pancuronium. Acta Anaesthesiol Scand. 1997;41(9):1095-1103.

13. Baillard C, Clec'h C, Catineau J, et al. Postoperative residual neuromuscular block: a survey of management. Br J Anaesth. 2005;95(5): 622-626.

14. Eriksson LI, Sundman E, Olsson R, et al. Functional assessment of the pharynx at rest and during swallowing in partially paralyzed humans: simultaneous videomanometry and mechanomyography of awake human volunteers. Anesthesiology. 1997;87(5):1035-1043.

15. Sundman E, Witt H, Olsson R, Ekberg O, Kuylenstierna R, Eriksson LI. The incidence and mechanisms of pharyngeal and upper esophageal dysfunction in partially paralyzed humans: pharyngeal videoradiography and simultaneous manometry after atracurium. Anesthesiology. 2000;92(4):977-984.

16. Eriksson LI. Reduced hypoxic chemosensitivity in partially paralysed man. A new property of muscle relaxants? Acta Anaesthesiol Scand. 1996;40(5):520-523.

17. Brull SJ, Murphy GS. Residual neuromuscular block: lessons unlearned. Part II: methods to reduce the risk of residual weakness. Anesth Analg. 2010;111(1):129-140.

18. Pai MP, Paloucek FP. The origin of the "ideal" body weight equations. Ann Pharmacother. 2000;34(9):1066-1069. 
19. Gätke MR, Viby-Mogensen J, Rosenstock C, Jensen FS, Skovgaard LT. Postoperative muscle paralysis after rocuronium: less residual block when acceleromyography is used. Acta Anaesthesiol Scand. 2002;46(2):207-213.

20. Murphy GS, Szokol JW, Marymont JH, et al. Intraoperative acceleromyographic monitoring reduces the risk of residual neuromuscular blockade and adverse respiratory events in the postanesthesia care unit. Anesthesiology. 2008;109(3):389-398.

21. Fuchs-Buder T, Hofmockel R, Geldner G, Diefenbach C, Ulm K, Blobner M. [The use of neuromuscular monitoring in Germany]. Anaesthesist. 2003;52(6):522-526.

22. Osmer C, Vogele C, Zickmann B, Hempelmann G. Comparative use of muscle relaxants and their reversal in three European countries: a survey in France, Germany and Great Britain. Eur J Anaesthesiol. 1996;13(4):389-399.

23. Bartkowski RR. Incomplete reversal of pancuronium neuromuscular blockade by neostigmine, pyridostigmine, and edrophonium. Anesth Analg. 1987;66(7):594-598.

24. Kopman AF, Kopman DJ, Ng J, Zank LM. Antagonism of profound cisatracurium and rocuronium block: the role of objective assessment of neuromuscular function. J Clin Anesth. 2005;17(1):30-35.

25. Backman SB, Bachoo M, Polosa C. Mechanism of the bradycardia produced in the cat by the anticholinesterase neostigmine. J Pharmacol Exp Ther. 1993;265(1):194-200.

26. Abrishami A, Ho J, Wong J, Yin L, Chung F. Sugammadex, a selective reversal medication for preventing postoperative residual neuromuscular blockade. Cochrane Database Syst Rev. 2009(4):CD007362.

27. Fuchs-Buder T, Meistelman C, Schreiber JU. Is sugammadex economically viable for routine use? Curr Opin Anaesthesiol. 2012;25(2):217-220.

28. Carron M, Baratto F, Zarantonello F, Ori C. Sugammadex for reversal of neuromuscular blockade: a retrospective analysis of clinical outcomes and cost-effectiveness in a single center. Clinicoecon Outcomes Res. 2016;8:43-52.

29. Baumgart A, Denz C, Bender H, et al. [Simulation-based analysis of novel therapy principles. Effects on the efficiency of operating room processes]. Anaesthesist. 2009;58(2):180-186.
30. Paton F, Paulden M, Chambers D, et al. Sugammadex compared with neostigmine/glycopyrrolate for routine reversal of neuromuscular block: a systematic review and economic evaluation. Br J Anaesth. 2010;105(5):558-567.

31. Fuchs-Buder T. Residual neuromuscular blockade and postoperative pulmonary outcome: the missing piece of the puzzle. Eur JAnaesthesiol. 2014;31(8):401-403.

32. Gaszynski T, Szewczyk T, Gaszynski W. Randomized comparison of sugammadex and neostigmine for reversal of rocuronium-induced muscle relaxation in morbidly obese undergoing general anaesthesia. Br J Anaesth. 2012;108(2):236-239.

33. Baillard C, Bourdiau S, Le Toumelin P, et al. Assessing residual neuromuscular blockade using acceleromyography can be deceptive in postoperative awake patients. Anesth Analg. 2004;98(3):854-857.

34. Carron M, Veronese S, Foletto M, Ori C. Sugammadex allows fast-track bariatric surgery. Obes Surg. 2013;23(10): 1558-1563.

35. Llauradó S, Sabaté A, Ferreres E, Camprubí I, Cabrera A. Postoperative respiratory outcomes in laparoscopic bariatric surgery: comparison of a prospective group of patients whose neuromuscular blockade was reverted with sugammadex and a historical one reverted with neostigmine. Rev Esp Anestesiol Reanim. 2014;61(10): $565-570$.

36. Ledowski T, Falke L, Johnston F, et al. Retrospective investigation of postoperative outcome after reversal of residual neuromuscular blockade: sugammadex, neostigmine or no reversal. Eur J Anaesthesiol. 2014;31(8):423-429.

37. Brueckmann B, Sasaki N, Grobara P, et al. Effects of sugammadex on incidence of postoperative residual neuromuscular blockade: a randomized, controlled study. Br J Anaesth. 2015;115(5): 743-751.

38. https://www.esahq.org. European Society of Anaesthesiology (ESA): POPULAR: POst-operative PULmonary Complications After Use of Muscle Relaxants in Europe (POPULAR); 2013 [updated: October 13, 2015]. Available from: http://m.esahq.org/research/clinical-trial-network/ ongoing-trials/popular/. Accessed November 17, 2015.
ClinicoEconomics and Outcomes Research

\section{Publish your work in this journal}

ClinicoEconomics and Outcomes Research is an international, peerreviewed open-access journal focusing on health technology assessment, pharmacoeconomics and outcomes research in the areas of diagnosis, medical devices, and clinical, surgical and pharmacological intervention. The economic impact of health policy and health systems
Dovepress

organization also constitute important areas of coverage. The manuscript management system is completely online and includes a very quick and fair peer-review system, which is all easy to use. Visit http://www.dovepress.com/testimonials.php to read real quotes from published authors. 